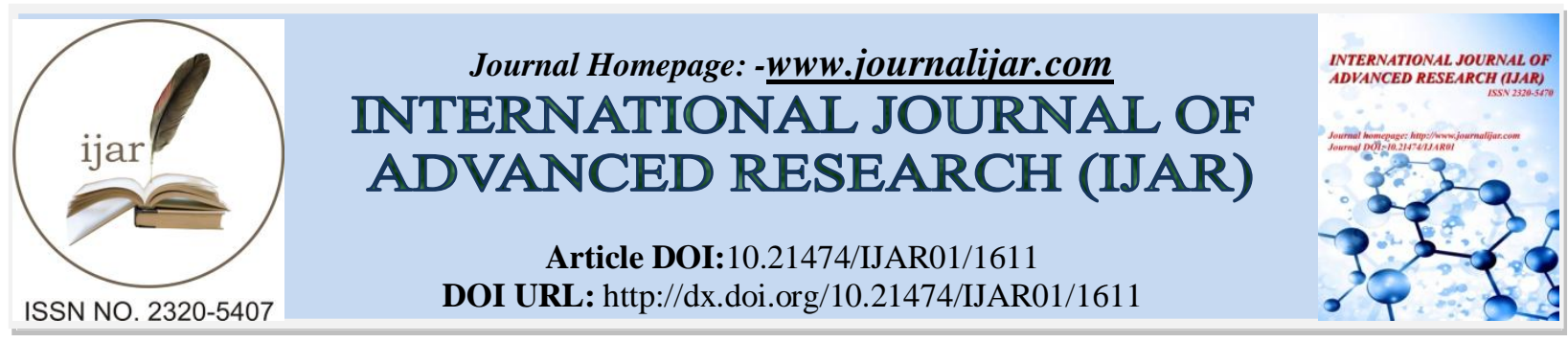

RESEARCH ARTICLE

\title{
A STUDY OF SERUM LIPID PROFILE IN CLINICALLY DIAGNOSED PATIENTS OF SENSORINEURAL HEARING LOSS.
}

Handique Gautom ${ }^{1}$, Das Monigopa ${ }^{2}$ and Gogoi Chandrika ${ }^{3}$.

1. GDMO, Department of Biochemistry, Assam Medical College and Hospital, Dibrugarh.

2. Associate Professor, Department of Biochemistry, Assam Medical College and Hospital, Dibrugarh.

3. Demonstrator, Department of Physiology, Assam Medical College and Hospital, Dibrugarh.

\section{Manuscript Info}

\section{Manuscript History}

Received: 12 July 2016

Final Accepted: 19 August 2016

Published: September 2016

Key words:-

Total cholesterol, Triglyceride, LDL, VLDL, HDL, SNHL.

\section{Abstract}

Background and Objectives:-Deafness one neglected chronic condition is the most prevalent sensory disability across nations and the etiology and pathogenesis of sensorineural hearing loss (SNHL), a type of deafness are not fully understood. Therefore this study was conducted to determine the correlation between serum lipid parameters and SNHL.

Material and Methods:- This hospital based case control study included a total of 108 subjects (54-control, 54-clinically diagnosed cases of SNHL), aged 18 years and above. In all the subjects a 12 hour fasting serum lipid parameters were estimated by colorimetric method using commercially available kits in semi auto analyser MICROLAB 300 (Merck).

Results:- The mean age of the cases was 48.31 years and of the control group was 43.96 years without any statistical difference ( $p$ > 0.05). Serum total cholesterol, triglyceride, LDL and VLDL levels were found to be increased and serum HDL level was found to be decreased in subjects with SNHL as compared to controls with a significance of $\mathrm{p}<0.001$. The level of serum triglyceride and VLDL increased with the severity of the degree of SNHL.

Conclusion:- Serum lipid profile can be used as an indicator of severity of SNHL as hyperlipidaemia seems to be significantly correlated with occurrence of SNHL.

Copy Right, IJAR, 2016,. All rights reserved.

\section{Introduction:-}

Hearing impairment is considered the most prevalent sensory impairment worldwide. Nationwide disability surveys have estimated hearing loss to be the second most common cause of disability ${ }^{1}$. SNHL is a type of hearing loss, or deafness, in which the root cause lies in the inner ear (cochlear), vestibulocochlear nerve (cranial nerve VIII), or central processing centers of the brain. However hearing may be worsened by some medical conditions such as hypothyroidism, diabetes, and possibly hyperlipidemia, among others ${ }^{2}$.

The modern lifestyle poses new challenges on the normal physiological mechanisms of the human body. The adverse impact of a sedentary lifestyle, excess body weight, and diets high in total and saturated fat superimposed on a genetic background confers susceptibility to increased circulating lipids. Dyslipidemia is one of the most 
significant cardiovascular risk factors ${ }^{3}$, and evidence has shown that there is relationship between SNHL and dyslipidemia $^{4,5,6}$. Several studies have demonstrated a relation between hyperlipidemia and hearing disorders. Various mechanisms by which hyperlipidemia might cause SNHL have been postulated and include atherosclerosis/ lipidosis/metabolic/ microvascular disease/ hypoxia/ embolic/ hyperviscosity/ hereditary/ ageing and hypertension ${ }^{7}$.

One of the root cause of SNHL which lies in the inner ear (cochlear), its function is greatly influenced by ischaemia since the blood supply of the inner ear is dependent on the end arteriole. Specifically related to the cochlea, the lipid composition, fluidity and stiffness of the outer hair cells internal wall membrane have been shown to be important to its electromotile function and the cochlear amplifier. The lateral wall plasma membrane of the outer hair cells also seems to have less cholesterol than other cells. So, the data suggests that outer hair cell function may be particularly sensitive to dyslipidaemic states.

\section{Objectives:-}

This study was undertaken to assess the serum lipid profile in the subjects with SNHL and also to see whether there was any correlation between serum lipid levels and severity of SNHL.

\section{Materials and methods:-}

A case control study was carried out among patients with SNHL and healthy subjects of age 18 years and above in the Department of Biochemistry, Assam Medical College and Hospital, Dibrugarh, Assam, for a period of 1 year from June 2014 to July 2015 . The study was conducted on 54 clinically diagnosed SNHL patients attending the Otorhinolaryngology Department of AMCH, Dibrugarh, Assam. Parallel to these cases, 54 healthy subjects of age and sex matched have been selected from normal population and their blood was also examined and this group was marked as control subjects.

In this study the degree of sensorineural hearing loss is classified on the basis of audiogram interpretation as Mild, Moderate, Moderately severe, Severe and Profound with hearing loss range of 26 to $40 \mathrm{db} \mathrm{HL}, 41$ to $55 \mathrm{db} \mathrm{HL}, 56$ to $70 \mathrm{db} \mathrm{HL}, 71$ to $90 \mathrm{db} \mathrm{HL}$ and $91+\mathrm{db}$ HL respectively.

Blood samples were drawn from all the patients after a minimum of 12 hours of fasting. About $5 \mathrm{ml}$ of blood was collected from antecubital vein after proper aseptic and antiseptic measures in sterile empty vial (SEV) for estimation of lipid profile. The sample collected was then allowed to clot. After being clotted the sample was allowed to centrifuge at $3000 \mathrm{rpm}$ for 10 minutes. The supernatant clear serum was then pipetted out using micropipettes with disposable tips. The samples were analyzed on the same day.

Following investigations were done to assess the lipid profile level in patients with SNHL and their correlation with various degree of hearing loss.

1. Serum Total Cholesterol by CHOD/PAP method.

2. Serum HDL Cholesterol by PEG/CHOD-PAP method.

3. Serum Triglyceride by GPO/PAP method.

4. Serum LDL-Cholesterol by using standard WHO approved Friedwald's formula.

5. Serum VLDL concentration is approximated by dividing plasma triglyceride by 5 .

Statistical analyses included Independent Samples T test, Chi-square test and ANOVA and all P-values $<0.05$ were considered as significant. 


\section{Results and Observations:-}

Age and sex distribution of the subjects are depicted in Figure 1 and Figure 2 respectively.

\section{Figure 1: Age distribution of the study population}

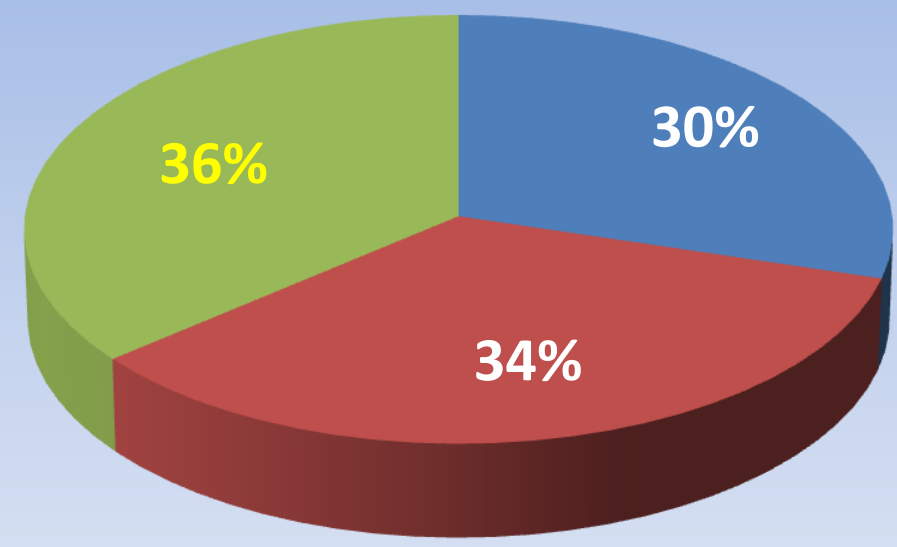

\section{8 to 35 years $\quad 35$ to 55 years $\quad 55$ and above}

It was found that $30 \%$ of the study population belonged to the age group of 18 to 35 years, $34 \%$ belonged to 35 to 55 years and $36 \%$ belonged to 55 years and above.

Figure 2: Gender distribution of the study population

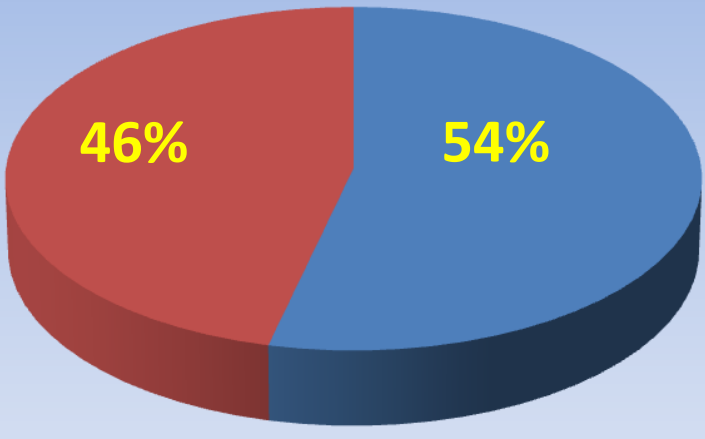

\section{MALE FEMALE}

On the basis of gender distribution of the study population, it was found that the male subjects were at $54 \%$ and females were at $46 \%$.

Table 1:- Table showing Gender wise distribution of cases and controls.

\begin{tabular}{|l|l|l|l|}
\hline Gender & Cases & Controls & p value \\
\hline Male & $29(53.7037 \%)$ & $29(53.7037 \%)$ & $>0.05$ \\
\hline Female & $25(46.2963)$ & $25(46.2963)$ & \\
\hline
\end{tabular}

Gender wise distribution did not show any significant association. 
Table 2:- Table showing mean age groups in cases and controls.

\begin{tabular}{|c|c|c|c|}
\hline Variables & Cases $($ Mean \pm SD) & Controls $($ Mean \pm SD) & p value \\
\hline Age in years & $48.31481 \pm 15.05816$ & $43.96296 \pm 16.42015$ & $>0.05$ \\
\hline
\end{tabular}

The mean age group in cases and controls did not show any significance.

Table 3:- Mean and standard deviation of serum lipid parameters in cases and controls

\begin{tabular}{|c|c|c|c|}
\hline Lipid parameters & $\begin{array}{c}\text { Case } \\
\text { (Mean } \pm \text { SD) } \\
(\mathrm{mg} / \mathrm{dl})\end{array}$ & $\begin{array}{c}\text { Control } \\
(\text { Mean } \pm \text { SD }) \\
(\mathrm{mg} / \mathrm{dl})\end{array}$ & P value \\
\hline Total Cholesterol & $196.30 \pm 7.74$ & $166.70 \pm 19.36$ & $<0.001$ \\
\hline Triglyceride & $156.19 \pm 8.75$ & $99.72 \pm 23.24$ & $<0.001$ \\
\hline LDL & $125.43 \pm 9.62$ & $100.74 \pm 16.89$ & $<0.001$ \\
\hline VLDL & $30.94 \pm 1.71$ & $19.57 \pm 4.68$ & $<0.001$ \\
\hline HDL & $39.44 \pm 12.33$ & $45.87 \pm 6.75$ & $<0.01$ \\
\hline
\end{tabular}

Table 3 shows that the level of serum total cholesterol, triglyceride, LDL and VLDL are elevated in cases with various degree of SNHL and serum HDL level is elevated in control subjects and the results were found to be highly significant with $\mathrm{p}<0.001$ and these findings are depicted in Figure 3.

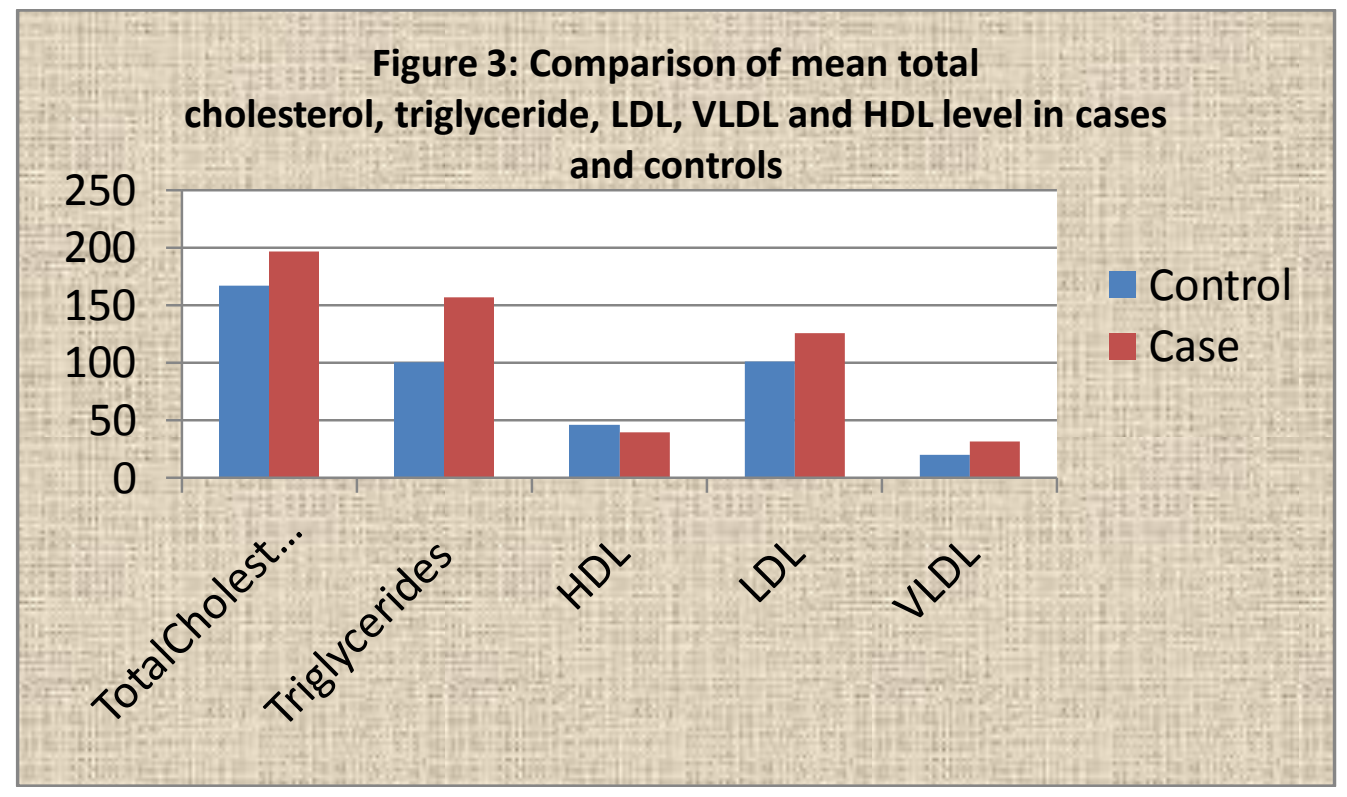

The mean values of serum lipids are also analysed with increase in degree of SNHL (Table $4 \&$ Figure 4 ).

Table 4:- Mean and standard deviation of lipid profile in various degree of SNHL.

\begin{tabular}{|l|c|c|c|c|c|c|}
\hline $\begin{array}{l}\text { Serum Lipid } \\
\text { Parameters in } \\
\text { mg/dl (Mean } \pm \\
\text { SD) }\end{array}$ & Mild & Moderate & $\begin{array}{l}\text { Moderately } \\
\text { severe }\end{array}$ & Severe & Profound & P - value \\
\cline { 2 - 8 } $\begin{array}{l}\text { Total } \\
\text { Cholesterol }\end{array}$ & $196.75 \pm 9.40$ & $195.82 \pm 9.27$ & $195.44 \pm 6.89$ & $197.33 \pm 6.98$ & $195.89 \pm 4.96$ & $>0.05$ \\
\hline Triglyceride & $157.5 \pm 8.56$ & $152.91 \pm 9.43$ & $149.33 \pm 7.57$ & $159.22 \pm 8.06$ & $161.67 \pm 4.58$ & $<0.05$ \\
\hline HDL & $38.81 \pm 10.20$ & $35.66 \pm 6.10$ & $34.89 \pm 8.83$ & $50.33 \pm 15.73$ & $38.89 \pm 16.19$ & 0.045 \\
\hline LDL & $126.06 \pm 9.38$ & $128 \pm 9.71$ & $\begin{array}{l}126.78 \quad 10 \\
10.46\end{array}$ & $119.58 \pm 8.22$ & $125.67 \pm 9.62$ & $>0.05$ \\
\hline VLDL & $31.25 \pm 1.69$ & $30.36 \pm 1.75$ & $29.56 \pm 1.42$ & $31.44 \pm 1.74$ & $32 \pm 1.71$ & $<0.05$ \\
\hline
\end{tabular}


Table 4 shows that the cases with profound degree of SNHL had the highest serum triglyceride values of 161.67 $\mathrm{mg} / \mathrm{dl}$ followed by severe group with $159.22 \mathrm{mg} / \mathrm{dl}$. Mean values of serum total cholesterol and LDL shows no correlation with various degree of SNHL ( $p>0.05$ ). Mean values of VLDL showed significant relationship with various degree of SNHL ( $<$ 0.05). By ANOVA p-value for serum HDL in various degree of SNHL found to be 0.045 .

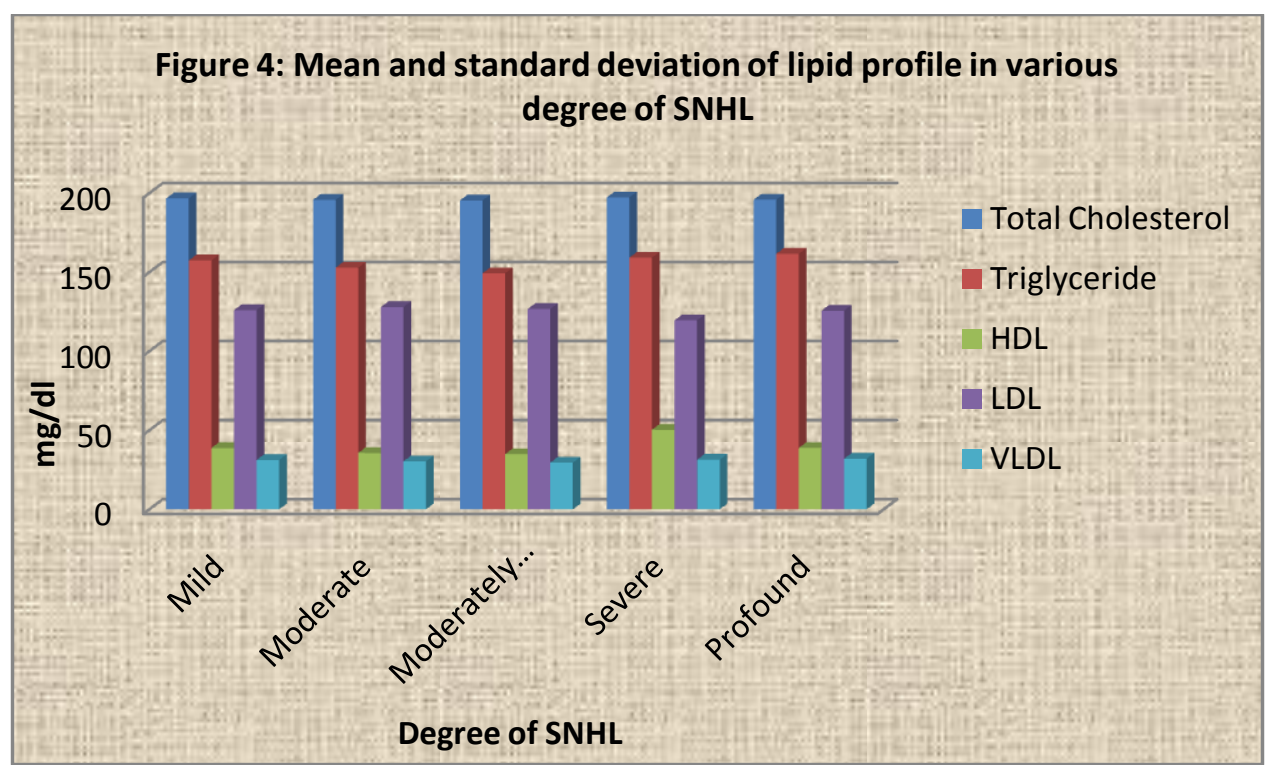

\section{Discussion:-}

Sensorineural hearing loss (SNHL) is a type of hearing loss, or deafness, in which the root cause lies in the inner ear (cochlear), vestibulocochlear nerve (cranial nerve VIII), or central processing centers of the brain. Inner ear function is greatly influenced by ischemia since the blood supply of the inner ear is dependent on the end arteriole ${ }^{8}$. Dyslipidemia is one of the most significant cardiovascular risk factors ${ }^{3}$, and evidence has shown that there is relationship between SNHL and dyslipidemia ${ }^{4,5,6}$. There are two primary lipoprotein fractions constituting total serum cholesterol: low-density lipoprotein cholesterol (LDL) and high-density lipoprotein cholesterol (HDL). Serum LDL transports cholesterol from the liver, via the circulatory system, to be deposited in other organs, specifically the arteries and heart. In contrast, HDL transports cholesterol from the organs and tissues back to the liver via the circulatory system. The HDL transport system is thought to be beneficial to the cardiovascular system because it reduces the formation of cholesterol plaques in major arteries. Elevated LDL and decreased HDL characterize coronary artery disease. In addition, an elevated serum triglyceride level is often present, indicating a high level of fat in the bloodstream. However, it is unclear whether dyslipidemia is associated with hearing loss.

So the present study aimed at assessing the serum lipid profile in subjects with sensorineural hearing loss and also to find out the correlation of dyslipidemia with various degrees of sensorineural hearing loss.

In this present study, elevated levels of total cholesterol, triglyceride, LDL and VLDL were found in the cases as compared to that of the controls $(\mathrm{p}<0.05)$. Serum HDL level was significantly higher in the control group $(<0.05)$. Among the subjects with various degrees of sensorineural hearing loss, triglyceride and VLDL showed increasing serum levels with the severity of the degree of hearing loss.

Our findings were consistent with the conclusion that dyslipidemia plays a role in the development of sensorineural hearing loss. Despite the fact that lipid parameters were estimated at only one point of time, a significant correlation between dyslipidemia and the various degrees of sensorineural hearing loss was found. This finding is in accordance with studies by Rosen et al. (1964) ${ }^{9}$, Karlidag T. et al. $(2002)^{10}$, Martin Villares C. et al. (2005) ${ }^{11}$, Sichkareva T.A. et al. $(2009)^{12}$, Jayson Nagaoka et al. (2010) ${ }^{13}$, and Chang SL. Et al. (2014) ${ }^{14}$. Thus the current study provides evidence for a critical role of dyslipidemia in the development of sensorineural hearing loss. 


\section{Conclusion:-}

In this study we found that there is an elevated level of serum total cholesterol, triglyceride, LDL and VLDL in cases as compared to the controls. Serum HDL level is significantly higher in the controls. With the severity of the degree of SNHL among the subjects of various degrees of SNHL, triglyceride and VLDL showed increasing serum levels.

The present study reveals a significant correlation of dyslipidemia with SNHL and can be used as an indicator of severity of SNHL. However, the present study had some limitations. One should be very cautious to draw any firm conclusion from this study as it was undertaken for a short span of one year's time with limited number of cases. It was a hospital based case control study; which does not claim to be a study of the population at large of this locality. Therefore, a final conclusion could not be made that there is a causal relationship between dyslipidemia and SNHL. Further study should be focused on cohort study on relationship between dyslipidemia and sensorineural hearing loss.

\section{Acknowledgement:-}

We are thankful to the Principal cum chief superintendent, Assam Medical College and Hospital, Dibrugarh for kindly allowing us to publish the hospital records.

Conflict of interest: Nil

Ethical clearance: Taken

Source of funding: Nil

References:-

1. Garg S, Chadha S, Malhotra S, Agarwal A. Deafness: Burden, prevention and control in India. THE NATIONAL MEDICAL JOURNAL OF INDIA. 2009;22(2):79-81.

2. Mathers, C., Smith, A., \& Concha, M. Global burden of hearing loss in the year 2000. Global burden of Disease. 2000:18, 1-30.

3. Wysokinski A, Kowman M, Kloszewska I: The prevalence of metabolic syndrome and Framingham cardiovascular risk scores in adult inpatients taking antipsychotics - a retrospective medical records review. PsychiatrDanub. 2012; 24:314-322.

4. Oreskovic Z, Shejbal D, Bicanic G, Kekic B: Influence of lipoproteins and fibrinogen on pathogenesis of sudden sensorineural hearing loss. J Laryngol Otol. 2011; 125:258-261.

5. Orita S, Fukushima K, Orita Y, Nishizaki K: Sudden hearing impairment combined with diabetes mellitus or hyperlipidemia. Eur Arch Otorhinolaryngol. 2007; 264:359-362.

6. Suzuki K, Kaneko M, Murai K: Influence of serum lipids on auditory function. Laryngoscope. 2000; 110:17361738.

7. Jones, NS. Davis, A. A prospective case-control study of patients presenting with idiopathic sensorineural hearing loss to examine the relationship between hyperlipidemia and sensorineural hearing loss. ClinOtolaryngol Allied Sci. 1999;24 (6), 531-6.

8. Rauch SD: Clinical practice. Idiopathic sudden sensorineural hearing loss. N Engl J Med. 2008; 359:833-840.

9. Rosen S, Plester D, El-Mofty A. Relation of hearing loss to cardiovascular disease. Trans Am AcadOphthalmolOtolaryngol. 1964;68:433-44.

10. Karlidağ T1, Açik Y, Kaygusuz I, Yalçin S, Güngör MY, Demirbağ E. The effect of hyperlipidemia on hearing function. Kulak BurunBogazIhtisDerg. 2002 Mar-Apr;9(2):112-6.

11. Martin, Villares C. San Roman, Carbajo J. Dominguez, Calvo J. Fernandez, Pello ME. Pomar, Blanco P. Tapia, Risueno M.. Lipid profile and hearing-loss age-related. Nutr Hosp. 2005, Jan-Feb;20(1): 52-7.

12. Sichkareva TA, Vishniakov VV, Kutepov DE. The role of plasmapheresis in the treatment of patients with sensorineural deafness. VestnOtorinolaringol. 2009;(3):36-8.

13. Jayson Nagaoka, Marcelo Ferreira dos Anjos, Thales Takeo Takata, Renan MoukbelChaim, Flavia Barros, Norma de Oliveira Penido. Idiopathic sudden sensorineural hearing loss: evolution in the presence of hypertension, diabetes mellitus and dyslipidemias. Braz J Otorhinolaryngol. 2010;76(3):363-9.

14. Chang SL, Hsieh CC, Tseng KS, Weng SF, Lin YS. Hypercholesterolemia is correlated with an increased risk of idiopathic sudden sensorineural hearing loss: a historical prospective cohort study.Ear Hear. 2014 MarApr;35(2):256-61. 